\title{
Support of the innovation activity in foreign practice
}

\author{
Anzhela Litvinova ${ }^{1, *}$, and Galina Gavlovskaya ${ }^{1}$ \\ ${ }^{1}$ RUDN-University, Department of National Economics of the Faculty of Economics, 117198, 6 \\ Miklukho-Maklaya str., Moscow, Russia
}

\begin{abstract}
The process of creation and development of innovations in Russia is slow enough and uneven on a number of reasons. The major obstacles for successful development of innovation activity on the territory of the country are the following: a lack of the necessary experience, picking up methods from the Western countries that are not always effective and factual lack of the complex approach to the organization of this activity at the federal level. This article is prepared with the support of the Program RUDN “5-100".
\end{abstract}

\section{Introduction}

The Russian and foreign desires to switch to the path of the postindustrial development have lately been conditioned by the necessity of creation of economy based on national and global innovation systems. If the global process of transition from the market economy to the innovation economy has been evolutional and started yet in the middle of the 20th century, in Russia it is now going spontaneously.

The purpose of this research is the study of foreign experience of development of the innovation activity, the tasks of which have been defined in absolutely new approaches, focused on the economic growth, stability and increasing social vector and the quality of life of the citizens. In the process of this study, theoretical, empirical and statistical methods have been used that allowed to assess results based on the analysis of theoretical data and on examples of other countries, and establish quantitative dependences between the research indicators. The basis of the hypothesis is a supposition that it will be possible to formulate a reasonable aggregate of innovative approaches to the development of innovation activities in Russia as one of the effective types of entrepreneurship as a result of the study of experience of the innovation activity support in foreign countries.

The study of foreign experience of different objects of innovation infrastructure is the major point for achieving the positive results, since most of the developed countries of the world embarked on the path of the innovative economy long ago. It means that these countries managed to accumulate significant experience, the study of which will allow to use successful results and avoid mistakes when introducing innovation into Russian practice.

\footnotetext{
* Corresponding author: ims-rpfu@ mail.ru
} 


\section{The innovation activity}

Today, this is the innovation activity that is the basis for dynamic development of all economic systems, and that influences on the level of competitiveness on both the internal and the international markets. Nowadays, the extent of the innovation development is the background of the economic development. For stimulating innovation processes in the developed countries of the world, national innovation systems were established yet in the middle of 1980s, and now they are considered the basis for the innovative economics.

Innovation system can accelerate the process of the economic growth of any country with the help of the effective mechanisms of receiving, transmitting and utilizing of the achievements of scientific and technological progress in the economic activity. For calculation of the index of the innovation development of a country, more than 80 different variables are used that characterize in details the development of the innovative spheres of different countries of the world, which are currently at different levels of their economic development. It is impossible to reject the fact that today wellbeing of national economy directly depends on its innovation potential and conditions for its implementation. On this reason, the index is calculated as a weighted sum of estimates of the two groups:

1) availability of resources and conditions for innovations (human capital, institutes, infrastructure, development of the internal market and business);

2) results achieved in the sphere of innovations (development of technologies and the knowledge economy, results of the innovative activity).

Therefore, the index of the innovation development is a cost / effect ratio that provides with a possibility to assess effectiveness of the results of the innovation activity in this or that country of the world.

The global index of innovation has been provided since 2007. Specialists examine the systems of education, infrastructure, the level of the business development, political situation in different countries and assess the innovation development relying on these parameters (Table 1).

Table 1. Index of innovation development of foreign countries (2015-2017).

\begin{tabular}{|l|l|c|c|c|c|c|c|}
\hline \multirow{2}{*}{ No Country } & \multicolumn{3}{c|}{$\begin{array}{c}\text { Index of innovation } \\
\text { development }(\%)\end{array}$} & \multicolumn{3}{c|}{ Rank in the world } \\
\cline { 3 - 8 } & & 2015 & 2016 & 2017 & 2015 & 2016 & 2017 \\
\hline 1 & Switzerland & 68.30 & 66.28 & 67.69 & 1 & 1 & 1 \\
\hline 2 & Great Britain & 62.42 & 61.93 & 60.89 & 2 & 3 & 5 \\
\hline 3 & Sweden & 62.40 & 63.57 & 63.82 & 3 & 2 & 2 \\
\hline 4 & Netherlands & 61.58 & 58.29 & 63.36 & 4 & 9 & 3 \\
\hline 5 & USA & 60.10 & 61.40 & 61.40 & 5 & 4 & 4 \\
\hline 6 & Finland & 59.97 & 59.03 & 58.49 & 6 & 5 & 8 \\
\hline 7 & Singapore & 59.36 & 59.16 & 58.69 & 7 & 6 & 7 \\
\hline 8 & Ireland & 59.13 & 59.03 & 58.13 & 8 & 7 & 10 \\
\hline 9 & Denmark & 57.70 & 58.45 & 58.70 & 10 & 8 & 6 \\
\hline 10 & Germany & 57.05 & 57.94 & 58.39 & 12 & 10 & 9 \\
\hline
\end{tabular}

Source: WIPO (World Intellectual Property Organization):

http://www.wipo.int/econ_stat/ru/economics/gii/ (Accessed: 01.12.2017).

The analysis of the statistical data for 2015, 2016, and 2017 indicates that since 2013 Switzerland, one of the richest countries of Europe has been the undisputed leader in the sphere of innovations. Then, with a fairly large margin follow the Great Britain and Sweden. It is worth to note that all countries on the top of this ranking are the economically developed countries. Luxembourg with an index of $59.02 \%$, and Hong Kong with an index $57.23 \%$ occupied respective the 9 th and the 11 th places, which were below the 10 th 
position in 2016 and 2017. In 2015, The Russian Federation was at the 48th place with the index of $39.32 \%$, in 2016 it was the 43 rd position with the index of $38.50 \%$, and in $2017-$ 45th with the index of 38.76 respectively. The neighbouring countries were Greece (the 44th place with the index of $38.85 \%$ ) and Chile (the 46th place, 38.70\%). Such developing countries as Zimbabwe, The Republic of Niger, Zambia, Togo, Guinea and Yemen closed the list.

Innovation and science and technological policy are differently executed in different countries of the global community. In different countries the distribution of functions between the market and the state is also different, and their organizational structures of science management leading to the stably high indicators differ from each other.

The following methods of direct stimulation of innovations are the most used in foreign countries: financing of the research and development (R\&D), crediting, providing in the preferential mode the state areas for carrying out research works, and large government orders.

The possibility of the state control of receipts and expenditures of funds allocated from the budget for innovation is the positive side of the direct funding. However, direct state funding gives rise to lobbying, corruption, and among other things, it increases the administrative costs on supporting the government initiatives.

For example, in Germany, the government invests money in the development of longterm and high-risk research in the leading branches of science and technological activity striving to improve its status in the innovation sector. In Canada, direct stimulation of R\&D by the state is based on the provision of long-term credits in the commercial banks and on funding R\&D by the state. Japan has government subsidies and concessional lending to public corporations and research centers that conduct R\&D jointly with private companies.

In addition to direct methods of impacting the development of innovation, there are some indirect measures, which create prerequisites for choosing a development strategy that meets the economic goals of the state.

In the developed countries of the world, the state actively supports innovation business through modernization of education, training of professional personnel and creation of management consultancies providing by these a high mobility of the labor force, and also through formation of the scientific and technological infrastructure. Recently, countries of Western Europe faced the issue of deficit of their own personnel in the sphere of information technologies. Tax, depreciation, credit and pricing policies and liberalization of the amortization and tax laws also belong to the indirect methods of management.

According to the global experience, tax benefits are the basic type of the state stimuli for innovation development. There are two kinds of the tax benefits: tax credits and tax rebates. In the global practice, tax rebate is interpreted as an amount which is subject to full or partial exclusion from the general tax base when calculating the total tax amount. Performing stimulating function in the development of innovation, tax rebates give a possibility to the companies that invest their own money in R\&D to have deductions, which are likely to exceed the costs of R\&D. Tax credit means deductions, as a percentage of R\&D expenditure, from the final tax liability of the entity that incurred the expenditure.

For the first time tax stimulation in the sphere of research and innovation was used in Japan in 1967. The largest national corporations utilized tax credits, and therefore increased their funding of R\&D. Tax credits can be mounted directly in proportion to the expenditure on R\&D (the volume tax credit). Also tax credits can be calculated on the basis of an increase in $R \& D$ expenses compared to the base year or the average for a specific period of time (the incremental tax credit), which is currently used in 11 countries of the world. For example, in France where the incremental tax credit is used, it is $30 \%$ from the first 100 million euro invested in R\&D. Herewith, an increase of up to $50 \%$ is under consideration 
for the newest innovative French companies that have invested in research and development of innovations for the first time [1].

Companies in the Great Britain, Denmark, Belgium and Australia actively use tax rebates. For example, there is a rebate of $13.5 \%$ for the Belgium companies.

In Japan, the rebate set as a percentage of the value of the implemented technology, is $5.3 \%$, in the Great Britain $-50 \%$ for the first year of the exploitation of the new equipment and materials, in Canada - some 10\%, and in Ireland - 100\%. In the USA, there are tax rebates for the energy equipment only.

However, there are countries, which do not provide any tax rebates and credits for R\&D (Germany, Finland, Iceland and Sweden), but their governments use other means to support and stimulate the development of innovations. For example, the government of Germany may reduce the amount of taxable profit of the research companies on the full value of $R \& D$ expenditure. There is a specific scheme of tax exempts for the $R \& D$ expenditures in private companies of Sweden and Finland.

Inter alia, there are tax incentives that facilitate interaction between the higher education sector and commercial firms and thus stimulate the development of innovations and research activity as a whole. For example, in the USA companies may reduce their tax base on the amount of cost of the research equipment presented to universities and noncommercial organizations.

The processes of financing and investing to the innovation spheres of activity are fundamentally different. In the global practice, the main source of financing for creation and development of research and innovation companies is venture capital. Venture capital is a risk and long-term capital that is invested in new and rapidly growing companies. Most of them are small high-tech enterprises of the innovation sector.

Most of the venture schemes are represented by independent funds attracting capital from the financial institutions before they invest it in small and medium-size firms. However, there are some financial institutions, which have their own venture funds, and also there is market of private investors and large corporations. Venture capital can be divided on a formal sector consisting of the funds of venture capital, funds, which specialize on supporting small science and technological enterprises, insurance companies, national companies, etc., and on informal sector represented by the legal entities, which conduct investment activity, by individuals, who have their own savings, etc. [2].

For example, funds of venture capital dominate in the USA, and they can be related to the formal sector. Specifically, these are commercial financial organizations, the major purpose of which is investing of the accumulated resources in the most interesting and perspective projects for getting profit. In most of the developed countries, the average volume of such funds is about USD 50 million (in the USA and the Great Britain is more then USD 90 million).

In Japan, the major part of investments into R\&D comes from private companies, up to $80 \%$. The share of the state investments in innovations is substantially lower as compared with the USA and European countries. In addition to that, the unification of the state and private companies in the form of special funds and program researches is of great importance.

National science foundations and committees on science also play an important role in the development of R\&D. As a rule, such foundations propose a list of programs on support of the innovation activity with the help of special grants and loans. Loans with low interest rates are prevalent in Western Europe and the United States. For example, in Finland, National technological agency (TEKES) provides with the amounts covering from 30 to $60 \%$ of the total expenditures for an innovation project. In Estonia, this type of funding is aimed at the support in development of scientific research and can cover $60-75 \%$ of all costs for a project. 
Loans contribute to the modernization of R\&D primarily in small and medium-size firms, and also in the organizations, which work on the commercialization of their own findings and research results. If an innovative project has not met expectations and has not received adequate returns, the loans can be partially repaid.

The programs on financing of $\mathrm{R} \& \mathrm{D}$ have been operating for some years in many European countries. For example, Finland actively uses financial opportunities of the European Union for carrying out its own research accessing resources that are much more than amounts of its specific-purpose contributions. The biggest all-European organizations, which regulate and redistribute financial resources, are The European Research Council and The European Science Foundation. Their creation was stimulated by the fact that the European Union tried to do its best in order not to lose its own competitiveness in the sphere of science and technology due to the insufficient funding into innovation and research projects, as compared with the amounts allocated by the USA and Japan.

The EU 7th Framework program is another important instrument of stimulation of investments in the European Union member states. The major purpose of the program is a provision of financial support to R\&D with the help of grants, which can cover up to $75 \%$ of expenses for the small and medium-size innovation enterprises. The total budget of this program is more than 50 billion euro and is focused on such directions, as [2]:

- improving European research and innovation development through cooperation between universities, industry, research institutes and the state across Europe and beyond;

- $\quad$ supporting the most promising research teams and scientists in Europe in all areas;

- preventing problem of "brain drain". Strengthening human resources capacity in the scientific field;

- providing financial support for $\mathrm{R} \& \mathrm{D}$, small and medium-size innovative enterprises, and activities aimed at the development of international cooperation.

\section{Findings}

The above programs not only become an effective tool for the development of scientific and innovation activities of individual countries, but also impact the development of the global scientific potential.

Contemporary global economy of the USA, one of the leaders in innovations, contributes to the development of innovations on the most of the scientific fields. About $60 \%$ of all technological innovations appeared there for the last five decades, and achievements of this country in development and commercialization of innovations in information, biotechnological, military and space, and environmental technologies are universally recognized. Today, the United States have the powerful and modern science and production basis, and, inter alia, possess significant state and corporate resources, which allow implementing large-scale innovation projects. The biggest one is considered the project of some USD $400-600$ million.

Germany, like the USA, is one of the leaders in many innovation indicators. As one of the most economically and innovatively effective countries of the world, Germany demonstrates its innovation potential in industry, and first of all in the small and mediumsize business. The share of German innovative enterprises is high enough in many branches of the economy. Thus, some $48 \%$ of industrial companies and $56 \%$ of servicing companies brought to the market about $37 \%$ of new innovative products and $41 \%$ of innovative production processes [3].

Japan is a vivid example of a country that uses the strategy of catching up innovative development to the maximum that is based on the utilization of the most effective global scientific achievements. Japan is trying to develop its own basic and applied sciences and thus ensuring the implementation of all major stages of the innovation process, from basic 
research to commercialization of innovations. According to the data for 2014-2016, Japan was the forth on the GNP volume, having just China, the USA and India ahead of it.

\section{Conclusion}

The global experience indicates that creation of favorable conditions for the development and improvement of $\mathrm{R} \& \mathrm{D}$ is the priority task of a state innovation policy. Elaboration of the advanced strategy interrelating science, the state and all spheres of the system of the economic space can stimulate development of effective innovations strengthening the economic system as a whole on the global and internal levels.

The authors express their gratitude to the Peoples' Friendship University of Russia (the RUDN University) for a possibility to establish communications in the space of science, and for support in the development of small innovation enterprise limited liability company "Innovation management systems". This article was produced with the support of the RUDN University program "5-100".

\section{References}

1. J. Routti, P. Yla-Antilla, The World Bank (Washington, 2014)

2. S. Luzan, N. Shandieva, Venture investments in Russia: the problems of development (In Russian). Investments in Russia, 4 (2006)

3. OECD Science. Technology and Industry Outlook 2008 (OECD Publishing, Paris, 2008).

4. I. V. Afonin, Innovatsionniy management: uchebnoe posobie (Gaardariki, Moscow, 2011)

5. J. S. Schumpeter, Theories of Economic Development (Economics, Moscow, 1995)

6. A. 1. Kleinkneeht, Innovation patterns in crisis and prosperity: Shumpeter's long cycle reconsidered (Hong Kong, 1987)

7. Electronic resource. Official website of the World Intellectual Property Organization (WIPO) (http://www.wipo.int/econ_stat/ru/economics/gii/)

8. Joseph Schumpeter and Gabriel Tarde on Technological Change and Social Evolution. 13th Annual International Conference of the European Society for the History of Economic Thought, April, 23-26, 2009 (Thessaloniki, Greece, 2009) 